Print ISSN: 2288-4637 / Online ISSN 2288-4645

doi:10.13106/jafeb.2020.vol7.no11.083

\title{
Modeling and Forecasting Saudi Stock Market Volatility Using Wavelet Methods
}

\author{
Tariq S. ALSHAMMARI ${ }^{1}$, Mohd T. ISMAIL ${ }^{2}$, Sadam AL-WADI ${ }^{3}$, Mohammad H. SALEH ${ }^{4}$, Jamil J. JABER ${ }^{5}$
}

Received: August 01, 2020 Revised: September 20, 2020 Accepted: October 05, 2020

\begin{abstract}
This empirical research aims to modeling and improving the forecasting accuracy of the volatility pattern by employing the Saudi Arabia stock market (Tadawul)by studying daily closed price index data from October 2011 to December 2019 with a number of observations being 2048. In order to achieve significant results, this study employs many mathematical functions which are non-linear spectral model Maximum overlapping Discrete Wavelet Transform (MODWT) based on the best localized function (B114), autoregressive integrated moving average (ARIMA) model and generalized autoregressive conditional heteroskedasticity (GARCH) models. Therefore, the major findings of this study show that all the previous events during the mentioned period of time will be explained and a new forecasting model will be suggested by combining the best MODWT function (B114 function) and the fitted GARCH model. Therefore, the results show that the ability of MODWT in decomposition the stock market data, highlighting the significant events which have the most highly volatile data and improving the forecasting accuracy will be showed based on some mathematical criteria such as Mean Absolute Percentage Error (MAPE), Mean Absolute Scaled Error (MASE), Root Means Squared Error (RMSE), Akaike information criterion. These results will be implemented using MATLAB software and R- software.
\end{abstract}

Keywords: MODWT's Functions, Saudi Stock Market, Volatility, GARCH Model, Forecasting

JEL Classification Code: M15, M27, M20, C40

\section{Introduction}

The Saudi stock market is considered as the largest financial markets in the developed countries. In addition, the Kingdom of Saudi Arabia's economy relies on oil as a major source of income, the stock market is expected

${ }^{1}$ First Author. School of Mathematical Science, Universiti Sains Malaysia, Penang, Malaysia. Email:hil_1989@hotmail.com

${ }^{2}$ Associate Professor, School of Mathematical Science, Universiti Sains Malaysia, Penang, Malaysia. Email: mtahir@cs.usm.my ${ }^{3}$ Corresponding Author, Associate Professor, Department of Risk Management and Insurance, Faculty of Business, The University of Jordan, Jordan [Postal Address: Queen Rania Street, Amman, Jordan] E-mail: sadam_alwadi@yahoo.co.uk

${ }^{4}$ Associate Professor, Department of Risk Management and Insurance, Faculty of Business, The University of Jordan, Jordan. E-mail: mohsaleh1966@yahoo.com

${ }^{5}$ Lecturer, Department of Risk Management and Insurance, Faculty of Business, The University of Jordan, Jordan.

E-mail: j.jaber@ju.edu.jo

(c) Copyright: The Author(s)

This is an Open Access article distributed under the terms of the Creative Commons Attribution Non-Commercial License (https://creativecommons.org/licenses/by-nc/4.0/) which permits unrestricted non-commercial use, distribution, and reproduction in any medium, provided the original work is properly cited. to cause sharp fluctuations depending on the fluctuations in the oil prices. Furthermore, Saudi Arabia is a member of the Group of Twenty (G20) which is the forum of international economic cooperation and includes leaders from 19 individual countries plus the European Union. The G20 member represents together about $80 \%$ of the global economy, two-thirds of the world's population, and threequarters of global trade volume. Moreover, Saudi Arabia is currently undertaking a package of economic reforms and opening up to the world. Finally, the Saudi stock market is suffering from sharp fluctuations during various periods due to its exposure to external crises.

The fluctuations in the returns of securities are gauged by the volatility in stock market. It indicates the behavior of security. It describes that if the price of a security fluctuates rapidly in a long/short period of time (high volatility) or if the price of a security fluctuates slowly in a long/short period of time (low volatility). Volatility is estimated by calculating the standard deviation of the annualized returns over a given period of time.

Volatility on the stock market, is measuring risky stocks, playing great importance for both market practitioners and policymakers, especially for emerging countries. Volatility 
in stock markets evokes varying responses from market participants. While some perceive it as an opportunity to make money, others perceive it as a threat, hence the practitioner is anxious about the stock market. The economist is trying to curb excessive volatility in order to ensure financial and macroeconomic stability. In this case, an appropriate quantitative method is required to model the stock market volatility to protect from undesired moving in prices.

Various studies report that stock market volatility is time-varying. This implies that changes in volatility are non-random. Therefore, practitioners and financial econometricians have developed a variety of time-varying volatility models that takes into account the fat tail, volatility clustering, and leverage effects. Poon and Granger(2003) provides a comprehensive review of volatility forecasting. They find that ARCH and GARCH classes of time series models are very useful in measuring and forecasting volatility. Tu and Liao (2020) the authors constructed the ACD model for the block trading volume using the GARCH model, IGARCH and FIGARCH models in order to construct a volatility model for Chunghwa Telecom (CHT) Inc., offering the America Depository Receipt (Finta et al., 2019) in NYSE, to investigate the block trading volume duration in Taiwanese equity market.

Nguyen and Nguyen(2019)studied the stock price volatility on Ho Chi Minh stock exchange by using GARCH, GARCH-M, EGARCH and TGARCH using daily closed price during 1/03/2001-1/03/2019 with 4375 observations. GARCH $(1,1)$ and EGARCH $(1,1)$ models are the best models to measure the volatility level of the data set used. Siddiqui and Erum(2016)studied the impact of exchange rate volatility, inflation, terms of trade, foreign direct investment and industrial production and foreign exchange reserves on Pakistani trade volume between 1975-2010 the Augmented Dickey Fuller, GARCH and Almon Polynomial Distributed Lag models are used to estimate the relationship of variables. Peiris \& Peiris(2011)studied the volatility and forecasting for index in different sectors in Colombo Stock Exchange using ARCH and the GARCH models.

Moreover,(Trinh et al., 2020)studied the relationship between financial macroeconomic fundamentals and the volatility of government bonds' borrowing cost in Vietnam for the period from 2006 to 2019 then make short, medium, and long term forecasting using Generalized Auto-Regressive Conditional Heteroskedasticity (GARCH) model, EGARCH, TGARCH.(Abdalla \& Suliman, 2012) investigate the GARCH models to estimate the market volatility of the Saudi stock market from 2007 to 2011. Tripathy and Garg (2013) examine time-varying risk and return for the greatest emerging markets using four alternative models GARCH; GARCH, EGARCH and TGARCH.

Kalyanaraman (2014) applied AR (1)-GARCH $(1,1)$ model to estimate the conditional volatility in the Saudi stock market from 2004 to 2013 . In the results, the author finds that a linear symmetric GARCH $(1,1)$ model is fit to estimate the volatility of the stock market, the Saudi stock market returns show a time-varying volatility and follow a non-normal distribution. Chaudhuri and Ghosh (2016) predict volatility in the Indian stock market using Artificial Neural Network (ANN) models. Ghosh and Chaudhuri (2016) used the Wavelet decomposition to examine three volatility indicators namely, CBOE VIX, INDIA VIX, and Historic Volatility (HV). Ismail, Audu, and Tumala (2016) used MODWT-GARCH $(1,1)$ model to forecast volatility in the African stock markets. They found that the MODWTGARCH $(1,1)$ model is a better model than GARCH $(1,1)$ directly in forecasting processes. They have used Daubechies function only in this paper.

Ahmad et al. (2016)used GARCH $(1,1)$ to estimate volatilities among six important stock markets in Asia from 2002 to 2009. They find the highest volatility in Hang Seng (Hong Kong) and the lowest volatility in KSE (Pakistan). Chatzikonstanti (2017) analyzed the volatility persistence of the U.S. stock market employing a wavelet-based algorithm. The results show that outliers associate with major events such as the 'Black Monday' and the Asian crisis. Johnsson (2018) predicts weekly volatility of three major stock indices (Swedish, British, and Australian). The purpose to apply ANNs and three various ARCH-type models $(\operatorname{GARCH}(1,1)$, EGARCH $(1,1)$ and TGARCH $(1,1))$. The results show no evidence of ANN predicting superiority for any of the three stock indices.

Shawer and Al-Ajlouni (2018)explored the relationship between the profitability proxy (ROI, ROE, and NPR) with the stock prices of petrochemical companies which is listed in the Saudi Stock Market during the period 2008 to 2015. The results show that the stock prices do not reflect profitability. In addition, the profit performance is varied by different profitability measures. Bin Ateeq (2018) using Autoregressive integrated moving average (ARIMA), Bayesian and Akaike analysis, Ljung-Box Q test, Partial autocorrelation function (PAC) to analyzing stock market volatility in three countries (Kuwait, UAE and Saudi Arabia). The result reveals that all countries are market inefficiencies and also changed as time progressed as result of liberalization, financial crises, and reform in the Middle East and North Africa (MENA) region.

Jarrah and Salim (2019) combined a discrete wavelet transforms (DWT) and a recurrent neural network (RNN) of the Saudi stock price trends. They found that the $(\mathrm{DWT}+\mathrm{RNN})$ are a more accurate prediction of the day's closing price compare with the ARIMA method based on three criteria namely; the mean squared error (MSE), root mean squared error (RMSE) and mean absolute error (MAE). (Finta et al., 2019) assess the volatility spillovers between oil with the US and Saudi Arabian stock markets. They found 
that the volatility spillover from oil to the stock markets is higher than the other way around.

Alsabban and Alarfaj (2020) investigated the investor's irrational behavior, specifically, overconfidence behavior in the Saudi stock market from 2007 to 2018. To test for overconfidence behavior, a market-wide Vector AutoRegression (VAR) model is designed to investigate the leadlag relationship between the market returns and the market turnover. The results obtained in this research suggest that investors in the Saudi stock market are overconfident. Jaber et al. (2020) used four WT functions to estimate credit loss.

The generalized autoregressive conditional heteroscedasticity $(\mathrm{GARCH})$ models are frequently in usage to examine the market volatility dynamics. The previous studies introduced many models to investigate the stock market volatility and evaluate the performance of stock market, such as ARCH, GARCH, EGARCH, TGARCH, FIGARCH. Further, there have been different studies that employed various models and their extensions to model the conditional variance, and they are found in both developed and emerging stock markets, such as(Abdalla \& Suliman, 2012; Lim \& Sek, 2013; Shaik \& Syed, 2019).

Volatility forecasting is especially important for institutions involved in options trading and portfolio management. Mathematical modeling can assist in establishing the relationship between current values of the financial indicators and their future expected values. Model based quantitative forecast with a valuable estimate of a future market trend. Modelling the volatility of financial time series is a primary area of investigation in financial economics and econometrics. The most common properties of volatility, the fat (heavy)-tailed distribution and volatility clustering, have been thoroughly analyzed particularly after the introduction of the seminal (G)ARCH models by(Engle, 1982; Bollerslev, 1986).

According to the mentioned literature review for the past decade, no researcher has focused on the application of MODWT to model volatility and improve the forecasting accuracy in the Tadawul. More pertinently, in terms of the objectives of this study, for the last 10 years a number of comparative studies using different methodologies have been carried out using various WT functions alone as well as in combination with other WT models. However, thus there is still room for further research into the comparative application of all MODWT functions which are (Haar, Daubechies (d4), coiflet (c4), least symmetric (LA8) and best localized (B114) in combination with suitable GARCH models in terms of just one particular context or financial market which this study shall undertake in relation to the Tadawul since some articles in the literature as mentioned before have used only one function of MODWT.

This study deals with the analysis of fluctuations in the Tadawul using MODWT functions. Where the index measures the performance of companies listed in the Saudi stock market, and the causes of fluctuations market, and modeling of variance behavior will be determined to reflect the accuracy of expectations and the percentage of potential risks.

Moreover, the forecasting accuracy will be improved and new forecasting model will be suggested by combining MODWT functions which are (Haar, Daubechies (d4), Coiflet (c4), Least Symmetric (LA8) and the Best Localized (Bl14) with GARCH model using statistical criterion such as MSE, RMSE, MAE and MAPE.

This article is organized as follows; the mathematical models will be discussed in section 2 . Then research design and methodology are explained in section 3 . Then data set and discussed results will be mentioned in section 4, finally, the conclusion in section 5 .

\section{Mathematical Models}

This section gives a background of the main concepts used in our study

\subsection{Wavelet Transform Formula}

Wavelet Transform (WT) is a mathematical function that is used to convert the original time series data into a time-scale domain. This model is very attractive to the nonstationary data especially stock market data. WT is divided into Discrete Wavelet transform (DWT), continuous wavelet transforms (CWT), and Maximum overlapping Wavelet transform (MODWT). These functions have the same aspects in general. The main difference between DWT and MODWT is that DWT can be used as a specified number of data (number of observations should be 2 of power J) while MODWT can be used for any size of data. Therefore in this article, we will focus on MODWT since it is more flexible and modern (Gençay et al., 2001).

Basically, WT is an extension to Fourier transform (FT), which is based on sine and cosine functions. WT satisfies the admissibility condition(JABER et al., 2020):

$$
C_{\varphi}=\int_{0}^{\infty} \varphi(f) \mathrm{V} \frac{\varphi(t)}{f} d f<\infty
$$

where $\varphi(f)$ is the FT and a function of frequency f, $\varphi(t)$. The WT is used in many applications such as image analysis and signal processing. It was introduced to overcome the problem of FT, especially when dealing with time, space, or frequency.

There are two types of WT which are Father wavelet describes the low-frequency parts (smooth data) and the mother wavelet describes the high-frequency (detailed data) 
components as shown in Equation (2) respectively, with $j=1,2,3, \ldots, J$ in the J-level wavelet decomposition:

$$
\begin{aligned}
& \phi j, k=2^{\left(\frac{-j}{2}\right)} \phi\left(t-\frac{2^{j} k}{2^{j}}\right) \\
& \varphi j, k=2^{\left(\frac{-j}{2}\right)} \varphi\left(t-\frac{2^{j} k}{2^{j}}\right)
\end{aligned}
$$

where $J$ denotes the maximum scale sustainable by the number of data points and the two types of wavelets stated above, namely father wavelets and mother wavelets and satisfies:

$$
\int \phi(t) d t=1 \wedge \int \varphi(t) d t=0
$$

The general mathematical model is resented in equation (4)

$$
S_{j, k}=\int \phi_{j, k} f(t) d t, d_{j, k}=\int \varphi_{j, k} f(t) d t,
$$

In more details,

$$
\begin{aligned}
F(t)= & \sum S_{j, k} \phi_{j, k}(t)+\sum d_{j, k} \varphi_{j, k}(t) \\
& +\sum d_{j-1, k} \varphi_{j-1, k}(t)+\ldots+\sum d_{1, k} \varphi_{1, k}(t)
\end{aligned}
$$

The WT is used to calculate the approximation coefficient in Eq. (6) where $S_{j}(t)$ and $D_{j}(t)$ are introducing the smooth and detailed coefficients respectively. The smooth coefficients content the most important features of the original data while the detailed coefficients are used to detect the main fluctuations of the original data.

Generally, WT has a popular transform function (Gençay et al., 2001), namely Haar, Daubechies (d4), coiflet (c6, Least Asymmetric (LA8), and the best-localized (b114). The number of main properties of these functions following. WT functions are arbitrary regular except Haar model. Interestingly, WT functions don't have explicit expression except Haar model. WT functions use real number. WT functions are orthogonal and compact support, arbitrary number of zero moments, existing of the scale function, orthogonal analysis, bio-orthogonal analysis, continuous / discrete transformation, exact reconstruction, and fast algorithm. The Haar model is symmetry. The LA8 and d4 are A Symmetry. Near Symmetry is associated with C6 and B114.

\subsection{Autoregressive Integrated Moving-Average Model (ARIMA)}

The auto-regressive moving average (ARMA) models are used in time series analysis to describe stationary timeseries. The ARMA model is a combination of a moving average (MA) model and an autoregressive (AR) model. A time series $\left\{e_{t}\right\}$ which is called a white noise (WN) process, $\left\{Y_{t}\right\}$ is called Gaussian process iff for all $t, e_{t}$ is iid $N\left(0, \sigma^{2}\right)$. A time series $\left\{Y_{t}\right\}$ is said to follow the $\operatorname{ARMA}(p, q)$ model if Jaber et al. (2020):

$$
\begin{aligned}
Y_{t}=\mu & +\phi_{1} Y_{t-1}+\phi_{2} Y_{t-2} \ldots+\phi_{p} Y_{t-p}+e_{t}-\theta_{1} e_{t-1} \\
& -\theta_{2} e_{t-2} \ldots-\theta_{q} e_{t-q}
\end{aligned}
$$

where $q$ and $p$ are non-negative integers, $p$ represents order of autoregressive part (AR), $q$ is defined as order of the first moving part (MA) and $\left\{e_{t}\right\}$ is the white noise $(\mathrm{WN})$ process. An extension of the ordinary ARMA model is the auto-regressive integrated moving-average model (ARIMA $(p, d, q))$ given by Jaber et al. (2020).

$$
\phi_{p}(B)(1-B)^{d} Y_{t}=\theta_{0}+\theta_{q}(B) e_{t}
$$

where $p, d$ and $q$ denote orders of auto-regression, integration (differencing) and moving average, respectively. When $d=0$, the ARIMA model reduces to the ordinary ARMA model.

\subsection{GARCH Model}

The autoregressive conditional heteroskedasticity (ARCH) is a statistical model introduced in 1982 by Robert Engle. This model is commonly used in financial time-series to exhibit volatility in financial market. The ARCH model is appropriate when the conditional variance follows an autoregressive (AR) and the return of stocks $\left(\mathrm{X}_{\mathrm{t}}\right)$ are split into a white noise stochastic process $\left(\mathrm{e}_{\mathrm{t}}\right)$ multiplied by the volatility $\left(\sigma_{t}\right)$. The ARCH (p) are modeled by (Chatfield \& Xing, 2019):

$$
\begin{gathered}
X_{t}=e_{t} \sigma_{t} \\
\sigma_{t}^{2}=\omega+\alpha_{1} X_{t-1}^{2}+\ldots+\alpha_{p} X_{t-p}^{2} \\
=\omega+\sum_{i=1}^{p} a_{1} X_{t-i}^{2},
\end{gathered}
$$

where $p$ is lag length and $e_{t} \sim N(0,1)$ is white noise i.i.d. with expectation 0 and variance 1 . 
(Bollerslev, 1986) generalized the ARCH (GARCH $(p, q)$ ) model to assume that $\sigma_{t}^{2}$ follows anautoregressive moving average model(ARMA). The GARCH $(\mathrm{p}, \mathrm{q})$ model (where $q$ is the order of the GARCH terms $\sigma^{2}$ and $p$ is the order of the ARCH term $\mathrm{X}^{2}$ ) is given by

$$
\begin{gathered}
X_{t}=e_{t} \sigma_{t} \\
\sigma_{t}^{2}=\omega+\alpha_{1} X_{t-1}^{2}+\ldots+\alpha_{p} X_{t-p}^{2}+\beta_{1} \sigma_{t-1}^{2}+\ldots+\beta_{q} \sigma_{t-q}^{2} \\
=\omega+\sum_{i=1}^{p} \alpha_{i} X_{t-1}^{2}+\sum_{i=1}^{q} \beta_{i} \sigma_{t-1}^{2}
\end{gathered}
$$

where standard deviation $\left(\sigma^{2}\right)$ remains positive if $\omega, \alpha_{i}$, $\beta_{\mathrm{i}} \geq 0$. GARCH model, depend on past squared return and past variances to model for current variance.

In particular, the simpler GARCH $(1,1)$ model, has been ideally used to analyze a number of different types of financial time series modelling and is common in most statistics and financial software packages. GARCH models describe financial markets in which volatility can change, becoming more volatile during periods of financial crises or world events and less volatile during periods of relative calm and steady economic growth. GARCH $(1,1)$ models are preferred over other stochastic volatility models by many financial professional researchers because of its relatively simple implementation: since they are given by stochastic difference equations in discrete time, the likelihood function is easier to handle than continuous-time models, and since financial data is generally gathered at discrete intervals.

\subsection{Volatility Computational}

In risk management, volatility is defined as the standard deviation of the continuously compounded return per day. Define $S_{i}$ as the close price at the end of day $i$. The continuously return per day for the close price on day $i$ as(Chatfield \& Xing, 2019):

$$
\mathrm{R}=\ln \frac{\mathrm{S}_{i}}{\mathrm{~S}_{i-1}}
$$

A variable's volatility, $\sigma_{t}$, is defined as the standard deviation of $R_{i}^{\prime} s$ at time t.

$$
\sigma_{t}=\sqrt{\frac{\sum_{i=1}^{n}\left(R_{i}-\bar{R}\right)^{2}}{n-1}}
$$

where $\overline{\mathrm{R}}$ is the arithmatic mean of the $\mathrm{R}_{\mathrm{i}}^{\prime} \mathrm{s}$. (Hull, 2012)

\subsection{Accuracy Criteria}

We use several types of accuracy criteria: the Mean absolute percentage error (MAPE), the Mean absolute scaled error (MASE), the Root means squared error (RMSE), the Akaike information criterion(AIC, AICs), the Bayesian information criterion (BIC). Where the MAPE criterion is also known as mean absolute percentage deviation (MAPD) that is a measure of prediction accuracy of a forecasting method in statistics. It usually expresses accuracy as a percentage, and is defined as $M A P E=\frac{\% 100}{n} \sum_{t=1}^{n}\left|\frac{X_{t}-F_{t}}{X_{t}}\right|$, where $X_{\mathrm{t}}$ is the actual value and $F_{\mathrm{t}}$ is the forecast value. The absolute value in this calculation is summed for every forecasted point in time and divided by the number of fitted points.

Also, the MASE is recommended for determining comparative accuracy of forecasts. It is estimated by $M A S E=\frac{\sum_{t=1}^{n}\left|X_{t}-F_{t}\right|}{\frac{n}{n-1} \sum_{t=2}^{n}\left|X_{t}-X_{t-1}\right|}$, where the numerator is the forecast error for a given period, defined as the actual value $\left(X_{\mathrm{t}}\right)$ minus the forecast value $\left(F_{\mathrm{t}}\right)$ for that period, and the denominator is the mean absolute error which uses the actual value from the prior period as the forecast: $F_{\mathrm{t}}=X_{\mathrm{t}-1}$. Next, The RMSE is known also as root-meansquare deviation (RMSD) that is a frequently used measure of the differences between estimators. It measures the average error performed by the model in predicting the outcome for an observation. It is defined as the square root of the mean square error as:

$$
\begin{aligned}
\text { RMSE } & =\sqrt{M S E} \\
& =\sqrt{\frac{\sum_{i=1}^{N}(\text { actualvalue }- \text { predictedvalue })^{2}}{N}}
\end{aligned}
$$

where $N$ represents the number of observations. Another accuracy criterion is AIC which is defined as AIC $=-2 * \log -$ likelihood $+k *$ npar, where npar represents the number of parameters in the fitted model, $k=2$, and $n$ being the number of observations, where AICc is a version of AIC corrected for small sample sizes. Finally, the $\mathrm{BIC}$ is $B I C=-2 * \log -$ likelihood $+k * n p a r$, where $n p a r$ represents the number of parameters in the fitted model, $k=\log (n)$, and $n$ being the number of observations (JABER et al., 2020). 


\section{Research Design and Methodology}

The objective of this research is to first, modeling the volatility data, second, discussing the fluctuations during the historical data issued from the Saudi stock market data in the period from 2017 to December 2019. Then finally, improving the forecasting accuracy. To do this, we have used the ARMA, ARIMA, GARCH and Wavelet models. We have considered the five MODWT functions which are: Haar, Daubechies (d4), least Asymmetric (La8), and Coiflet (C6) and the best-localized (bl14). Further, we make use of the accuracy criteria to compare our models.

We have proposed several models to forecast the closed price stock market data which have been collected from the Saudi stock market. We have used a wavelet transform to convert the original data into a time-scale domain. Then we have combined the MODWT with the ARIMA, ARMA and GARCH model to improve the forecasting accuracy. We studied various functions of MODWT to evaluate our models. Figure 1 draws the different steps of the MODWT forecasting process.

We noted that when the data pattern is very rough, the wavelet process is repeatedly applied. The aim of preprocessing is to minimize the statistical criteria such as Root Mean Squared Error (RMSE) between the signal before and after transformation. The noise in the original data can thus be removed. Importantly, the adaptive noise in the training pattern may reduce the risk of over fitting in the training phase. Thus, we adopt MODWT twice for the pre-processing of the training data in this study.

Further, the Maximum overlapping Wavelet transform (MODWT) converts the data into two sets; details series (DA1 (n)) and approximation series (CA1 (n)). These two series give good behavior for the data set especially with the financial data since it significantly fluctuates. Then, the transformed data can be anticipated more precisely. The purpose behind the good behavior of these two series is the filtering effect of the MODWT. Additionally, we have used the approximation series since the series behave as the main component of the transform.

To handle our data, our methodology can be summarized as follows: First: modeling the volatility data using the return series. Second, we break down through the MODWT functions which are (Haar, Daubechies (d4), coiflet (c4), least symmetric (LA8) and the best localized (B114) the available historical return data. Third: we use the details series to detect the fluctuations and go through the historical volatility data. Fourth: we use a fitted GARCHARIMA model fitted to the approximation series to make the forecasting. Finally, the new technique is compared with a pure ARIMA and ARMA-GARCH model used directly to forecast the closed price data series by utilizing the specified criteria.

In order to make a far comparison, we do the following; applying $90 \%$ of the dataset (original data and the transformed data) for the suggested model, then selecting the best model. Then applying the best model with the other suggested models for the rest data $(10 \%)$. Therefore, in this step we can confirm that our new model is better than the others specifically.

\section{Empirical Results}

In this section, we present the data used in our study. Then we give the numerical results obtained when applied our models to the considered dataset.

Table 1: Descriptive statistic of returns and closing prices in Saudi stock market

\begin{tabular}{|c|c|c|c|}
\hline & & Return & Closed Price \\
\hline \multicolumn{2}{|l|}{ N } & 2026 & 2027 \\
\hline \multicolumn{2}{|l|}{ Minimum } & -0.0755 & 5416.4700 \\
\hline \multicolumn{2}{|l|}{ Maximum } & 0.0855 & 11149.3600 \\
\hline \multicolumn{2}{|l|}{ Mean } & 0.0002 & 7735.5495 \\
\hline \multicolumn{2}{|c|}{ Std. Deviation } & 0.0107 & 1156.9609 \\
\hline \multirow{2}{*}{ Skewness } & Statistic & -0.5497 & 0.5519 \\
\hline & Std. Error & 0.0544 & 0.0544 \\
\hline \multirow{2}{*}{ Kurtosis } & Statistic & 10.7936 & -0.1951 \\
\hline & Std. Error & 0.1087 & 0.1087 \\
\hline
\end{tabular}




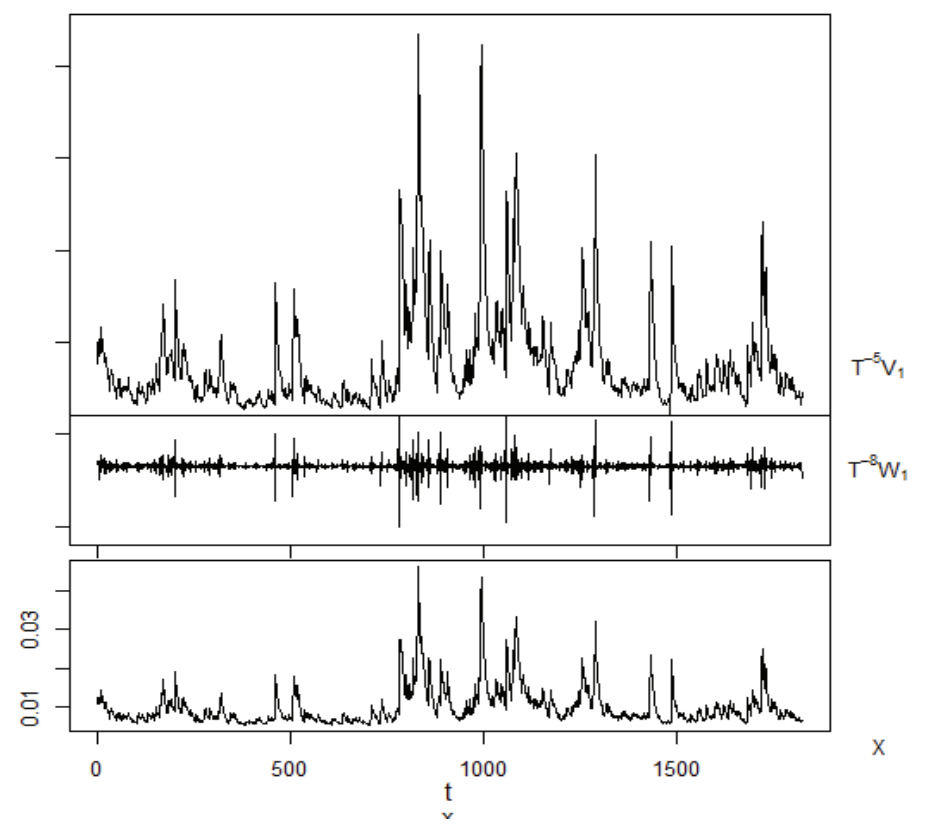

Figure 1: Decomposing the data using MODWT based on $\mathrm{Bl} 14$ function

\subsection{Data Description}

The sample data of closing prices are collected from stock market (Tadawul) in Saudi Arabia. The day-to-day closing prices was collected from $10^{\text {th }}$ August 2011 until 31 December 2019. The size of sample is 2027. The total number of observations for mathematical convenience in orthogonal wavelet transform is suggested to be divisible by $2^{\mathrm{j}}(\mathrm{j}=1,2,3, \ldots$ ) (Gençay et al., 2001; JABER et al., 2020). Table 1 shows the descriptive statistic of returns and closing prices.

\subsection{Results and Discussion}

The current study examines the volatility pattern of the Saudi stock market (Tadawul). It is chosen for different reasons; the emerging markets have interesting historical experience for stock market volatility. The Saudi market as an example has significant volatility due to an imbalance in information, random trading, and unprofessional financial analysis. In addition, the investors of other countries except the Gulf Cooperation Council (GCC)are not allowed to invest in Saudi stocks.

The Saudi stock market (Tadawul) is the largest in the Middle East. Therefore, the volatility data will be decomposed in the following figure using a modern function which is bl14. Then the fluctuations during the selected period will be discussed.
Figure 1 illustrates the decomposition of the dataset used data of B114 function from the WT model. As shown in Figure 1, this method is a suitable method to use to reveal the fluctuations, magnitudes, and phases for the closing price data from the dataset. The application of the MODWT (B114) to the historical data decomposes them into a variety of resolution levels that expose their essential structure and it generates detailed coefficients at each one of the decomposition levels. According to the WT mechanism, the levels of decomposition can be carried out by the WT using the following equation: $\mathrm{X}=\mathrm{TV} 1+\mathrm{TW} 1$. Where $\mathrm{X}$ refers to the original signal. Then the next part consists of one approximation level (TV1) which shows the plot of the approximation coefficients for the transformed data. The following parts of TW1 represent the level of details, whereby, TW1 is the plot of the first level of the detail coefficients, therefore, this level can be used to explain the fluctuation. Tadawul was established in the Kingdom of Saudi Arabia in 2007. According to the Kingdom's vision in 2030, the Saudi financial market will be the main market in the Middle-East and one of the ten most important finTW1zancial markets in the world to attract domestic and foreign investment. Moreover, there are several activities taken to liberalize the market that have many positive effects; including stimulating capitals, increasing liquidity, reducing the cost of capital, increasing growth in total investment, growth of small and medium-sized companies, and increasing the efficiency of the market. These measures 
are part of a package of economic reforms in the Kingdom Saudi Arabia, which aimed to develop the financial sector and raise its competitiveness, in line with the Kingdom's vision in 2030 .

In 2015, the Saudi stock market allowed trading for foreign investors. In 2018, a series of reforms are executed such as the law of foreign investors by the Saudi stock market. In 2019, the credit rating agencies (FTSE, Russell, S\&P, and Dow Jones) are started working in emerging markets. Furthermore, the number of companies increased to 199 companies, and the market value of shares issued reached (2406.78) billion US dollars. Moreover, the number of foreign investors increased by $163.7 \%$ (to 1,195 investors).

The fluctuation in stock prices and returns is one of the challenges that effect the various economies in the world. The Saudi stock market is affected by domestic and international economies. The external financial crises are transmitted to the domestic markets. In 2008, the Saudi stock market was affected by the global financial crisis.(Shaik \& Syed, 2019).

The Saudi stock market has experienced various fluctuations from 2011 to 2019. It was noticed in 2011 that the general index decreased to (6417.7) points, while the index increased in 2013 to reach (8535) points. The market management has modified the trading system from (SAXESS) to (X-Stream INET) as well as developing an interactive multi-user system (IFSAH) to improve the efficiency and effectiveness of the market(Alotaibi et al., 2018).

The degree of concentration is one reason for fluctuations in the Saudi stock market. The individual investors have a lion share in the stock market. The percentage of individual investors is about $86.9 \%$, domestic institutions are approximately $11.8 \%$, and the foreign investors are lowest at $1.2 \%$ in 2014 . Moreover, the financial and petrochemical sectors are approximately $51.6 \%$ of the total market value in 2014(Al-Bassam \& Holderness, 2006).In 2015, the Saudi stock market decreased approximately by $2.5 \%$ due to decrease in the profits of the petrochemical industries sector (Banafe \& Macleod, 2017).

Oil prices play a crucial role in the fluctuations in the stock market over time in Saudi Arabia. The high oil prices stimulate foreign capitals to invest in Saudi Arabia. This stimulation affects the fluctuation in the stock market by an increase in the per capita income, the exchange rate of the domestic currency, and inflation rate as a result of an increase in the money supply. On the other hand, the low oil prices affect the decrease in stock prices. In 2015, the Saudi stock market had fluctuations as a result of the international economy which includes a decline in commodity prices and a sharp decline in the Chinese stock market. The Saudi financial market fell about $17.1 \%$ as a result of fall in oil prices by about $40 \%$. Moreover, the volatility was during the 90 days approximately was $22.2 \%$ which is the highest volatility since 2009 . The negative movements of oil prices affected the stock market. Indeed, the relationship on oil prices and the Saudi financial market is instability over time.

The Saudi financial market was exposed during 2016 to the liquidity risk and volatility risk. The decline in oil prices about $11.1 \%$ and government reforms led to a decrease in the purchasing power of people as a result of adding tax, lower government spending, lower private consumption, lower corporate profitability, and decline in real estate company stock prices. This drop contributes in decline in earnings of the Saudi stock market about 4.1\%. In 2017, there is limited fluctuations near $13.5 \%$, due to the improvement in oil prices. The investor behavior also affects market instability. For example, the investor's overconfidence leads to high circulation and increased demand, which leads to an increase in stock price's arbitrary (Alsabban \& Alarfaj, 2020).

At the end of 2018, the financial market in developed countries had large waves of selling stocks, which extended to undeveloped countries. However, the Saudi stock market currently has many challenges that will increase fluctuations in the short term as a result of the economic recession, the decline in oil prices, the Covid-19 epidemic, and conflict interest between the United States and China. Therefore, improving prediction accuracy is a very serious problem facing researchers, thus in this article CARCH-ARIMAMODWT will be combined together to improve prediction accuracy. The fitted GARCH model should be selected in Table 2, then the following table will show that GARCH $(1,1)$ is the fit model since it has lass AIC and BIC. Table 3 shows parameters of GARCH $(1,1)$.

Table 2 gives the results of the suggested models for the first $90 \%$ of the data set used. The ARIMA-Direct is the model obtained when we apply the pure ARIMA model directly on the original data. ARIMA-MODWT (Haar) is the combination of the GARCH $(1,1)$ model with Haar function. ARIMA-MODWT (d4) is the combination of the GARCH $(1,1)$ model with Daubechies function (d4). ARIMA-MODWT (LA8) is the combination of the GARCH $(1,1)$ model with the least square model (LA8) function. ARIMA-MODWT (B114) is the combination of the GARCH $(1,1)$ model with the best localized (B114) function. ARIMAMODWT (C6) is the combination of the GARCH $(1,1)$ model with Coiflet (C6) function. Finally, we compare the result for ARMA- GARCH $(1,1)$. Then the best model is ARIMAMODWT (B114) since it has a minimum value of RMSE, MAE, MAPE and MASE which are $0.000188,0.000100066$, $0.967305,0.165123$ respectively with fit ARIMA $(1,1,5)$.

In order to confirm our results, the forecasting using the rest $10 \%$ of the transformed and original data will be implemented using the same suggested models. Therefore, we have found that the best model is ARIMA-MODWT (B114) since it has minimum value of RMSE, MAE, MAPE and MASE fit ARIMA $(1,1,5)$ as seen in Table 4. 
Table 2: Selecting the fitted GARCH model

\begin{tabular}{|l|c|c|c|c|}
\hline & AIC & BIC & SIC & HQIC \\
\hline GARCH(1,1) & -6.521251 & -6.510168 & -6.521259 & -6.517185 \\
\hline GARCH $(2,1)$ & -6.520084 & -6.506229 & -6.520096 & -6.5150 \\
\hline GARCH $(1,2)$ & -6.520953 & -6.507099 & -6.520965 & -6.515869 \\
\hline GARCH(2,2) & -6.519966 & -6.503341 & -6.519984 & -6.513866 \\
\hline
\end{tabular}

Table 3: The following results shows the properties of GARCH $(1,1)$

\begin{tabular}{|l|c|c|c|c|}
\hline & Estimate & Std.Error & t-value & $\operatorname{Pr}(>|\mathbf{t}|)$ \\
\hline $\mathrm{Mu}$ & $6.48 \mathrm{E}-04$ & $1.90 \mathrm{E}-04$ & 3.411 & 0.000648 \\
\hline Omega & $4.54 \mathrm{E}-06$ & $8.24 \mathrm{E}-07$ & 5.512 & $3.54 \mathrm{E}-08$ \\
\hline alpha1 & $1.50 \mathrm{E}-01$ & $2.11 \mathrm{E}-02$ & 7.097 & $1.27 \mathrm{E}-12$ \\
\hline beta1 & $8.23 \mathrm{E}-01$ & $2.07 \mathrm{E}-02$ & 39.727 & $<2 \mathrm{e}-16$ \\
\hline
\end{tabular}

Table 4: GARCH- MODWT models for $90 \%$ of observations

\begin{tabular}{|l|l|c|c|c|c|c|}
\hline Sample $\%$ & $\begin{array}{c}|c| \\
\text { GARCH- } \\
\text { MODWT models }\end{array}$ & ARIMA(p, $\mathbf{d}, \mathbf{q})$ & RMSE & MAE & MAPE & MASE \\
\hline \multirow{5}{*}{$\begin{array}{l}\text { 90\% of } \\
\text { observations }\end{array}$} & Haar & $(3,1,0)$ & 0.003995683 & 0.003133484 & 47.37026997 & 0.93273925 \\
\cline { 2 - 7 } & d4 & $(3,1,0)$ & 0.004044933 & 0.003187519 & 48.65340701 & 0.932755842 \\
\cline { 2 - 7 } & la8 & $(1,1,3)$ & 0.004526673 & 0.003751524 & 63.01218723 & 0.932333411 \\
\cline { 2 - 7 } & bl14 & $(1,1,5)$ & 0.003752519 & 0.002871695 & 41.40596664 & 0.933029401 \\
\cline { 2 - 7 } & c6 & $(2,1,2)$ & 0.004312974 & 0.003495695 & 56.25117223 & 0.932659109 \\
\cline { 2 - 7 } & ARIMA-direct & $(0,1,0)$ & 0.003986859 & 0.003124038 & 47.14592031 & 0.932722908 \\
\cline { 2 - 7 } & ARMA\&GARCH & $(1,1)$ & 0.009513924 & 0.009168369 & 1718.167921 & \\
\hline \multirow{5}{*}{$\begin{array}{l}10 \% \text { of } \\
\text { observations }\end{array}$} & Haar & $(3,1,0)$ & 0.000879504 & 0.000426495 & 3.603613727 & 0.722484661 \\
\cline { 2 - 7 } & d4 & $(3,1,0)$ & 0.000758414 & 0.000381683 & 3.187069714 & 0.649892914 \\
\cline { 2 - 7 } & la8 & $(1,1,3)$ & 0.000321021 & 0.000163712 & 1.552446635 & 0.274478353 \\
\cline { 2 - 7 } & bl14 & $(1,1,5)$ & 0.00018837 & 0.000100066 & 0.967304797 & 0.165123194 \\
\cline { 2 - 7 } & c6 & $(2,1,2)$ & 0.00053854 & 0.000255738 & 2.34441569 & 0.432394939 \\
\cline { 2 - 7 } & ARIMA-direct & $(0,1,0)$ & 0.001583186 & 0.000745588 & 6.102212651 & 0.999459995 \\
\cline { 2 - 7 } & ARMA\&GARCH & $(1,1)$ & 0.00946491 & 0.008419692 & 83.38987087 & \\
\hline
\end{tabular}

Figure 2 shows the diagrams of past and forecasting values of data used using MODWT functions combined with ARIMA model and GARCH- ARIMA- MODWT (B114) function. According to the numerical results, GARCHARIMA- MODWT (B114) function succeeds in finding good results compared to the pure ARIMA-MODWT directly.

\section{Conclusion}

In this article, the volatility pattern of the Saudi Arabia stock market (Tadawul) is modeled and studied using all closed price indexes from October 2011 to
December 2019. The volatility data was examined and modeled by using a non-linear spectral model which is the Maximum Overlapping Discrete Wavelet Transform (MODWT) based localized function (B114). Some of the fluctuations and events were discussed. Therefore, all the previous events during the mentioned period of time will be explained. Moreover, the suggested model which is GARCH- ARIMA- MODWT (B114) is the best model compared with other suggested models. As a result, the ability of MODWT in decomposition, highlighting the significant events and forecasting were shown. 
Volatility for $90 \%$ of sample - Forecasting for $10 \%$ of sample

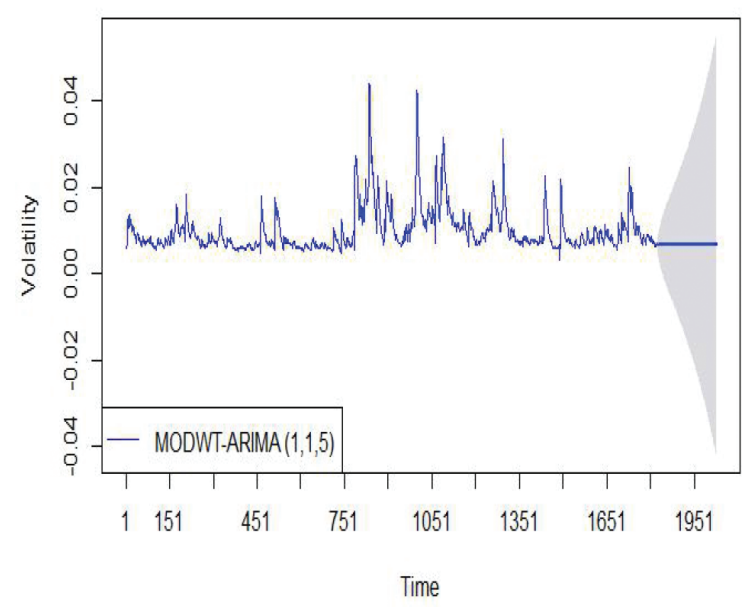

(a) WT's functions.

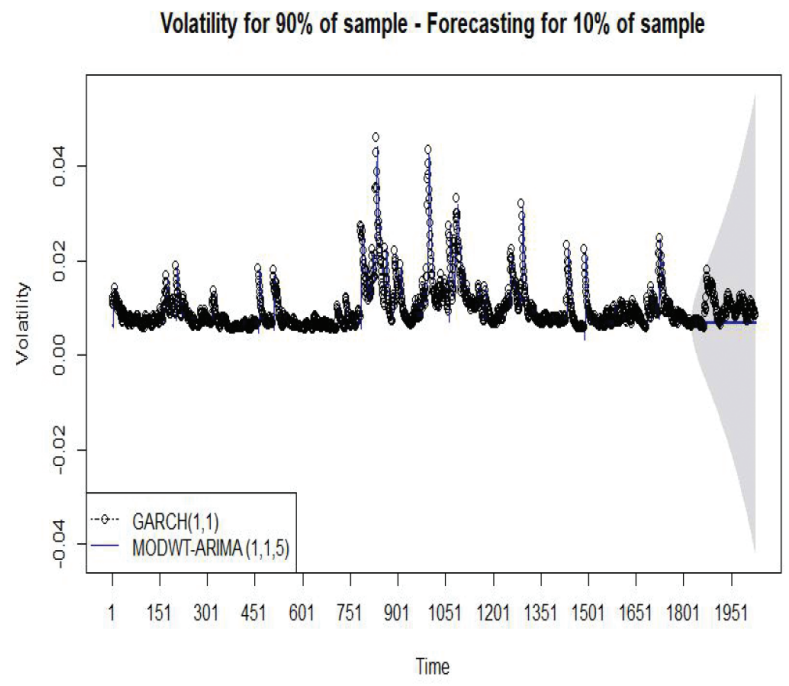

(b) GARCH- ARIMA- MODWT (BI14) function

Figure 2: Forecasting diagram from WT's functions and GARCH- ARIMA- MODWT (BI14) function

\section{References}

Abdalla, S. Z. S., \& Suliman, Z. (2012). Modelling stock returns volatility: Empirical evidence from Saudi Stock Exchange. International Research Journal of Finance and Economics, 85(2012), 166-179.

Ahmad, N., Raheem A., R., Vveinhardt, J., \& Streimikiene, D. (2016). Empirical analysis of stock returns and volatility: Evidence from Asian stock markets. Technological and Economic Development of Economy, 22(6), 808-829.

Al-Bassam, S., \& Holderness, G. (2006). The Al-Hamlet Summit. Hatfield, England: UH Press.

Alotaibi, T., Nazir, A., Alroobaea, R., Alotibi, M., Alsubeai, F., Alghamdi, A., \& Alsulimani, T. (2018). Saudi Arabia stock market prediction using Neural Network (NN). International Journal on Computer Science and Engineering, 10(2), 62-69. http;// http://doi: 10.21817/ijcse/2018/v10i2/181002024

Alsabban, S., \& Alarfaj, O. (2020). An empirical analysis of behavioral finance in the Saudi stock market: Evidence of overconfidence behavior. International Journal of Economics and Financial Issues, 10(1), 73-86. http:// RePEc:eco:journ1:2020-01-10

Banafe, A., \& Macleod, R. (2017). The Saudi Arabian Monetary Agency, 1952-2016: Central Bank of Oil. Brrlin, Germany: Springer.

Bin Ateeq, Y. A. I. (2018). Assessing for the volatility of the Saudi, Dubai and Kuwait stock markets: time series analysis (20052016).Manchester Metropolitan University.
Bollerslev, T. (1986). Generalized autoregressive conditional heteroskedasticity. Journal of Econometrics,31(3),307-327. https://EconPapers.repec.org/RePEc:eee:econom:v:31:y: 1986:i:3:p:307-327

Chatfield, C., \& Xing, H. (2019). The analysis of time series: an introduction with $R$. Cleveland, $\mathrm{OH}$ : CRC Press.

Chatzikonstanti, V. (2017). Breaks and outliers when modelling the volatility of the US stock market. Applied Economics, 49(46), 4704-4717. http:// DOI: 10.1080/00036846.2017.1293785

Chaudhuri, T. D., \& Ghosh, I. (2016). Forecasting volatility in Indian stock market using artificial neural network with multiple inputs and outputs.International Journam of Computer Applications, 120(8), 7-15. http:// doi:10.5120/21245-4034.

Engle, R. F. (1982). Autoregressive conditional heteroscedasticity with estimates of the variance of United Kingdom inflation. Econometrica: Journal of the Econometric Society,50(4) 9871007.https://www.jstor.org/stable/1912773

Finta, M. A., Frijns, B., \& Tourani-Rad, A. (2019). Volatility spillovers among oil and stock markets in the US and Saudi Arabia. Applied Economics, 51(4), 329-345. http:// DOI: 10.1080/00036846.2018.1494811

Gençay, R., Selcuk, F., \& Whitcher, B. J. (2001). An introduction to wavelets and other filtering methods in finance and economics. Amsterdam, the Netherlands: Elsevier.

Ghosh, I., \& Chaudhuri, T. (2016). Understanding and forecasting stock market volatility through wavelet decomposition, statistical learning and econometric methods. In: Conference: 
4th International Conference on Business Analytics and Intelligence (ICBAI 2016), Indian Institute of Science, Bangalore, India.

Hull, J. (2012). Risk management and financial institutions. Hoboken, NJ: John Wiley \& Sons.

Ismail, M. T., Audu, B., \& Tumala, M. M. (2016). Volatility forecasting with the wavelet transformation algorithm garch model: Evidence from african stock markets. The Journal of Finance and Data Science, 2(2), 125-135. https://doi. org/10.1016/j.jfds.2017.03.001

Jaber, J. J., Ismail, N., Ramli, S., Al Wadi, S., \& Boughaci, D. (2020). Assessment of Credit Losses Based on ARIMA-Wavelet Method. Journal of Theoretical and Applied Information Technology, 98(09), 1379-392. http:// http://www.jatit.org/ volumes/Vo198No9/5Vo198No9.pdf

Jarrah, M., \& Salim, N. (2019). A recurrent neural network and a discrete wavelet transform to predict the Saudi stock price trends. International Journal Advanced Comput. Science Application, 10(4), 155-162. http://doi: 10.14569/IJACSA.2019.0100418

Johnsson, O. (2018). Predicting stock index volatility using Artificial Neural Networks (ANN): An empirical study of the OMXS30, FTSE100 \& S\&P/ASX200. LUND UNIVERSITY LIBEARIES. Master Thesis. http://lup.lub.lu.se/studentpapers/record/8946583

Kalyanaraman, L. (2014). Stock market volatility in Saudi Arabia: An application of univariate GARCH model. Asian Social Science, 10(10), 142. DOI:10.5539/ass.v10n10p142

Lim, C. M., \& Sek, S. K. (2013). Comparing the performances of GARCH-type models in capturing the stock market volatility in Malaysia. Procedia Economics and Finance, 5, 478-487. http:// doi: 10.1016/S2212-5671(13)00056-7

Nguyen, C. T., \& Nguyen, M. H. (2019). Modeling stock price volatility: empirical evidence from the ho chi minh city stock exchange in Vietnam. Journal of Asian Finance, Economics and Business, 6(3), 19-26. http:// DOI : https://doi.org/10.13106/ jafeb.2019.vol6.no3.19

Peiris, T., \& Peiris, T. (2011). Measuring stock market volatility in an emerging economy. Digital Repository. http://www.kln. ac.lk/uokr/ICBI2011/A\&F\%20152.pdf

Poon, S.H., \& Granger, C. W. (2003). Forecasting volatility in financial markets: A review. Journal of Economic Literature, 41(2), 478-539. http:// DOI: 10.1257/002205103765762743

Shaik, A., \& Syed, A. (2019). Intraday return volatility in Saudi Stock Market: An evidence from Tadawul All Share Index. Management Science Letters, 9(7), 1131-1140. doi: 10.5267/j. ms1.2019.3.012.

Shawer, M., \& Al-Ajlouni, A. (2018). Impact of profitability on stock market value: Evidence from petrochemical industry in Saudi Arabia. Journal of Administrative and Economic Sciences, 11(2), 23-47.

Siddiqui, M. A., \& Erum, N. (2016). Modeling effect of exchange rate volatility on growth of trade volume in Pakistan. Journal of Asian Finance, Economics and Business, 3(2), 33-39. doi: 10.13106/jafeb.2016.vol3.no2.33.

Trinh, Q. T., Nguyen, A. P., Nguyen, H. A., \& Ngo, P. T. (2020). Determinants of Vietnam government bond yield volatility: A GARCH approach. Journal of Asian Finance, Economics, and Business, 7(7), 15-25. https://doi.org/10.13106/jafeb.2020. vol7.no7.015

Tripathy, N., \& Garg, A. (2013). Forecasting stock market volatility: Evidence from six emerging markets. Journal of International Business and Economy, 14(2), 69-93.

Tu, T.T., \& Liao, C.W. (2020). Block trading based volatility forecasting: An application of VACD-FIGARCH Model. Journal of Asian Finance, Economics, and Business, 7(4), 5970. https://doi.org/10.13106/jafeb.2020.vol7.no4.59 